\section{Figure number}

A Time course of paw mechanical threshold after SNL

B Time course of MLL1 expression in the dosal horn after SNL

Figure number

A MLL1 expression in the dosal horn after MLL1 siRNA

treatment in naïve rats

B Time course of performance after MLL1 siRNA treatment in

2 C The ipsilateral mechanical threshold of sham rats with MLI

The ipsilateral mechanical threshold of SNL rats with MLL

siRNA treatment

E MLL1 expression in the ipsilateral dosal horn after MLL1 siRNA treatment in SNL rats

Figure number

A mGluR5 mRNA expression in the ipsilateral dosal horn after MLL1 siRNA treatment in SNL ras

mGluR5 expression in the ipsilateral dosal horn after MLL

C mGluR5 promoter fragments immunoprecipitated by MLL1-

3 specific antibodies after MLL1 siRNA treatment in SNL ral

D Time course of H3K4me3 expression in the dosal horn after SNL

mGluR 5 promoter fragments immunoprecipitated by

H3K4me3- specific antibodies after MLL1 siRNA treatment

\section{Figure number}

A Number of positive cells

B Time course of WDR5 expression in the dosal horn after SNL

Figure number

WDR5 expression in the dosal horn after WDR5 siRNA

treatment in naïve rats

Time course of performance after WDR5 siRNA treatment in naïve rats

5 C The ipsilateral mechanical threshold of sham rats with WDR5

C siRNA treatment

D The ipsilateral mechanical threshold of sham rats with WDR6

siRNA treatment

E WDR5 expression in the ipsilateral dosal horn after WDR5

siRNA treatment in SNL rats

Figure number

\section{Sample size (n) Statistical analyses}

$\mathrm{n}=6 /$ group Two-way ANOVA with Tukey' $\mathrm{s}$ post-hoc tes Two-way ANOVA with Tukey' s s post-hoc test

\section{Sample size ( $n$ )}

$\mathrm{n}=5 /$ group

Sample size (n)

Statistical analyses

n=6/group

\section{Statistical analyses}

$n=6 /$ group

Two-way ANOVA with Tukey's spost-hoc test

n=6/group

Two-way ANOVA with Tukey' s post-hoc test Statistical analyses

n=5/group

Sample size ( $n$

n=5/group

n=5/group

n=5/group

Sample size (n)

n=5/group

Sample size (n)

$n=5 /$ group

Sample size (n)

n=5/group

n=5/group

Sample size (n)

n=5/group

Sample size (n)

$\mathrm{n}=6 /$ group

$\mathrm{n}=6 /$ group

$\mathrm{n}=6 /$ group

Sample size (n)

$\mathrm{n}=5 /$ group

Sample size (n)

One-way ANOVA with Tukey' s post-hoc test

One-way ANOVA with Tukey's post-hoc test

One-way ANOVA with Tukey's sost-hoc test

Statistical analyses Unpaired t-tests

Statistical analyses

One-way ANOVA with Tukey's s post-hoc test

\section{Statistical analyses}

Unpaired t-tests

\section{Statistical analyses}

Two-way ANOVA with Tukey' s post-hoc test

One-way ANOVA with Tukey’ s post-hoc tes Statistical analyses

Two-way ANOVA with Tukey' s post-hoc tes

Two-way ANOVA with Tukey's post-hoc test

Two-way ANOVA with Tukey' s post-hoc test Statistical analyses

One-way ANOVA with Tukey' s post-hoc test

\section{tatistical analyses}

Time effect

$\mathrm{F}(4,80)=4.842, \mathrm{P}=0.001$

$F(3,48)=8.501, P=0.0001$

Group effect

$\mathrm{F}(3,20)=49.97, \mathrm{P}<0.000$

$\mathrm{F}(3,16)=44.91, \mathrm{P}<0.000$

interaction

$F(12,80)=2.860, P=0.0025$

\section{Main effect}

$F(6,28)=6.985, P=0.000$

Two-way ANOVA with Tukey' s post-hoc test or

\section{Time effect}

$\mathrm{F}(4,80)=0.3482, \mathrm{P}=0.8445$

$\mathrm{F}(4,80)=1.812, \mathrm{P}=0.1347$

$\mathrm{F}(4,80)=66.01, \mathrm{P}<0.000$

Main effect

$\mathrm{F}(2,12)=6.291, \mathrm{P}=0.0135$

\section{Main effect}

$F(3,16)=66.36, P<0.0001$

\section{Group effect}

$\mathrm{F}(3,20)=0.5809, \mathrm{P}=0.6344$

$\mathrm{F}(3,20)=2.458, \mathrm{P}=0.0926$

$\mathrm{F}(3,20)=7.093, \mathrm{P}=0.0020$

\section{Group effect}

$F(3,16)=6.398, P=0.0047$

\section{Interaction}

$F(1,16)=12.57, P=0.0027$

\section{Main effect}

$\begin{aligned} & \text { HKK 4me3 } \mathrm{F}(3,16)=23.21, \mathrm{P}<0.000 \\ & \mathrm{~F}(3,16)=0.2468, \mathrm{P}=0.861\end{aligned}$

MLL1 $\quad \mathrm{P}=0.0028$

WDR5 $\quad \mathrm{P}=0.0019$

MERGE $P=0.0065$

Time effect
$\mathrm{F}(3,48)=28.36, \mathrm{P}<0.0001$

Main effect

$\mathrm{F}(6,28)=6.192, \mathrm{P}=0.0003$

Time effect

$F(4,80)=1.669, P=0.1653$

$\mathrm{F}(4,80)=1.452, \mathrm{P}=0.2247$

$\mathrm{F}(4,80)=86.03, \mathrm{P}<0.0001$

Main effect

$\mathrm{F}(2,12)=6.520, \mathrm{P}=0.0121$

Time effect

\section{Group effect}

$F(3,20)=2.062, P=0.1376$

$F(3,20)=0.8562, P=0.4798$

$F(3,20)=15.65, P<0.0001$

\section{Interaction}

$\mathrm{F}(12,80)=1.472, \mathrm{P}=0.1525$

$\mathrm{F}(12,80)=1.039, \mathrm{P}=0.422$

$\mathrm{F}(12,80)=4.495, \mathrm{P}<0.000$
Interaction

$\mathrm{F}(9,48)=25.81, \mathrm{P}<0.0001$

\section{Interaction}

$\mathrm{F}(12,80)=1.603, \mathrm{P}=0.1073$

$\mathrm{F}(12,80)=0.8307, \mathrm{P}=0.6188$

$\mathrm{F}(12,80)=4.299, \mathrm{P}<0.0001$ 

B The ipsilateral mechanical threshold of SNL rats with

C The contralateral mechanical threshold of SNL rats with WDR5-0103 treatment

mGluR5 mRNA expression in the ipsilateral dosal horn after

F mGluR5 expression in the ipsilateral dosal horn after mGluR5 promoter fragments immunoprecipitated by MLL1specific antibodies after WDR5-0103 treatment in SNL rats

mGluR5 promoter fragments immunoprecipitated by WDRS-

specific antibodies after WDR5-0103 treatment in SNL rats mGluR5 promoter fragments immunoprecipitated by

H3K4me3-specific antibodies after WDR5-0103 treatment in

\section{Figure numbe}

A Time course of paw mechanical threshold after SN

B Time course of MLLI expression in the dosal horn after SN Time course of WDR5 expression in the dosal horn after SN C The ipsilateral mechanical threshold of SNI rats with

$7 \mathrm{D}$ mGluR5 $\mathrm{mRNA}$ expression in the ipsilateral dosal horn after MCluR5 promoter framents imm

ated by MLL1 GluR5 promoter fror WDR5-0103 treatment in SNI rats

E mGluR5 promoter fragments immunoprecipitated by WDR mGluR5 promoter fragments immunoprecipitated by

H3K4me3- specific antibodies after WDR5-0103 treatment in

\section{Figure number}

mGluks promoter fragments in specific antibodies after WDR5 siRNA treatment in SNL rats

mGluR5 promoter fragments immunoprecipitated by WDR5specific antibodies after WDR5 siRNA treatment in SNL rats mGluR5 promoter fragments immunoprecipitated by

H3K4me3-specific antibodies after MLL1 siRNA treatmen or

MLL1 expression in the ipsilateral dosal horn after

MLL1 siRNA treatmen or WDR5 siRNA treatment in SNL rats

WDR5 expression in the ipsilateral dosal horn after MLL1 siRNA treatmen or WDR5 siRNA treatment in SNL rats

B H3K4me3 expression in the ipsilateral dosal horn after MLL1 siRNA treatmen or WDR5 siRNA treatment in SNL rats $\mathrm{H} 3$ expression in the ipsilateral dosal horm after MLL1 siRNA treatmen or WDR5 siRNA treatment in SNL rats mGluR5 expression in the ipsilateral dosal horn after MLL1 siRNA treatmen or WDR5 siRNA treatment in SNL rats

C The mechanical threshold of Naïve rats with CHPG treatment The mechanical threshold of SNI rats with MLL1 siRNA treatmen or WDR5 siRNA treatment+CHPG treatment $\mathrm{n}=6 /$ group

Two-way ANOVA with Tukey' s post-hoc test

Sample size (n)

\section{tatistical analyses}

n=6/group

One-way ANOVA with Tukey’ s post-hoc test

n=5/group

One-way ANOVA with Tukey's post-hoc tes

=5/group

$\mathrm{n}=5 /$ group

n=5/group

$\mathrm{n}=5 /$ group

Sample size ( $\mathbf{n}$

$\mathrm{n}=5$ /group

=4/group

n=4/group

n=5/group

Sample size (n)

n=4/group

n=5/group

$=5$ /group

n=5/group

Sample size (n)

n=5/group

$\mathrm{n}=5$ /groun

$\mathrm{n}=5$ /group

$\mathrm{n}=5$ /group

$\mathrm{n}=5$ /group

$\mathrm{n}=5$ /group

n=5/group

n=5/group

$\mathrm{n}=5 /$ group

$\mathrm{n}=5$ /group
One-way ANOVA with Tukey’ s post-hoc test

ay ANOVA with Tukey's sost-hoc test

One-way ANOVA with Tukey' s post-hoc test
$F(6,150)=19.56, P<0.0001$ Main effect

$F(2,15)=0.2393, P=0.790$

$\mathrm{F}(3,16)=58.31, \mathrm{P}<0.000$

$F(3,16)=10.42, P=0.000$

MLL1 $\quad F(3,16)=45.06, P<0.0001$

$\begin{array}{ll}\operatorname{lgG} & \mathrm{F}(3,16)=0.4259, \mathrm{P}=0.737 \\ \text { WDR5 } & \mathrm{F}(3,1)=17.55, \mathrm{P}<0.000\end{array}$

$\begin{array}{ll}\mathrm{F} & \mathrm{F}(3,16)=17.85, \mathrm{P}<0.0001 \\ \mathrm{GG} & \mathrm{F}(3,16)=0.9241, \mathrm{P}=0.45\end{array}$

H3K4me3 $F(3,16)=113.9, \mathrm{P}<0.000$

$\operatorname{IgG} \quad \mathrm{F}(3,16)=1.296, \mathrm{P}=0.310$

\section{Time effect}

$\mathrm{F}(4,64)=2.282, \mathrm{P}=0.070$ $<<0.000$ $F(2,24)=7.298, P=0.0033$

$F(6,72)=6.246, P<0.0001$

$F(3,16)=14.04, P<0.0001$

MLL1 $\quad F(3,16)=20.87, P<0.0001$

$\begin{array}{ll}\operatorname{lgG} & \mathrm{F}(3,16)=0.09482, \mathrm{P}=0.9618 \\ \mathrm{WDR} 5 & \mathrm{~F}(3,16)=7.760, \mathrm{P}=0.020\end{array}$

$\mathrm{IgG} \quad \mathrm{F}(3,16)=0.5152 \mathrm{P}=0.6776$

H3K4me3 $\mathrm{F}(3,16)=45.54, \mathrm{P}<0.0001$

$\log \quad F(3,16)=0.3251, P=0.8072$

\section{Main effect}

MLL1 $\quad F(3,16)=52.88, P<0.0001$

IgG $\quad F(3,16)=0.2693, P=0.8466$

NDR5 $\quad F(4,20)=16.82, P<0.000$

$\operatorname{IgG} \quad \mathrm{F}(4,20)=1.385, \mathrm{P}=0.2748$

H3K4me3 $F(3,16)=155.9, \mathrm{P}<0.0001$

$\operatorname{lgG} \quad F(3,16)=0.1788, P=0.9092$

$\mathrm{F}(4,20)=15.16, \mathrm{P}<0.0001$

$F(4,20)=8.513, P=0.0004$

$\mathrm{F}(4,20)=8.770, \mathrm{P}=0.0003$

$F(4,20)=0.2899, P=0.881$

$F(4,20)=15.39, P<0.0001$

$\mathrm{F}(4,20)=13.77, \mathrm{P}<0.0001$

$F(5,24)=16.49, P<0.0001$

\section{Group effect}

$P(3,16)=90.79, P<0.000$

$P=0.0024$

$\mathrm{F}(3,12)=6.408, \mathrm{P}=0.0077$

$\mathrm{F}(2,12)=82.16, \mathrm{P}<0.000$
$\mathrm{F}(24,150)=4.373, \mathrm{P}<0.0001$

$(12,64)=2.365, P=0.0137$ $(6,24)=9.848, P<0.000$ $F(6,24)=4.684, P=0.0028$ $\mathrm{F}(12,72)=4.789, \mathrm{P}<0.000$ 


\begin{tabular}{|c|c|}
\hline & $\begin{array}{l}\text { Two-way ANOVA with Tukey's post-hoc test: } \\
\text { Two-way ANOVA analysis found that the mechanical threshold of SNL IPSI decreased with time }(\mathrm{F}(4,80)=4.842, p= \\
0.0015) \text {; and was different from groups }\left(\mathrm{F}_{(3,20)}=49.97, p<0.0001\right) \text {; and displayed a clear group by time interaction }(\mathrm{F} \\
(12,80)=2.860, p=0.0025) \text {. } \\
\text { Post-hoc analyses comparing groups at each time point: } \\
\text { Post-hoc analyses comparing the Sham IPSI group and SNL IPSI group at each time point was NS }(p>0.05) \text { at day }-1 \text {, } \\
\text { but were significant at days } 3,7,14 \text {, and } 21 \text { ( } p=0.0035, p<0.0001, p<0.0001 \text { and } p<0.0001) \\
\text { Post-hoc analyses comparing time points of each group: } \\
\text { SNL IPSI were significant at days } 3,7,14 \text { and } 21 \text { when compared with SNL IPSI day }-1(p=0.0014, p<0.0001, p< \\
0.0001 \text { and } p<0.0001) \text {. } \\
\text { Results indicated SNL IPSI had a lower mechanical threshold on days } 3,7,14 \text {, and } 21 \text { than other groups. }\end{array}$ \\
\hline Fig. 1B & $\begin{array}{l}\text { Two-way ANOVA with Tukey's post-hoc test: } \\
\text { Two-way ANOVA analysis found that MLL1 expression in the dorsal horn of SNL IPSI increased with time }(F(3,48)=8.501 \text {, } \\
p=0.0001) \text {; and was different from groups }\left(F_{(3,16)}=44.91, p<0.0001\right) \text {; and displayed a clear group by time interaction } \\
(\mathrm{F}(9,48)=9.709, p<0.0001) \text {. } \\
\text { Post-hoc analyses comparing groups at each time point: } \\
\text { Post-hoc analyses comparing the Sham IPSI group and SNL IPSI group at each time point were NS }(p>0.05) \text { at day - } \\
1 \text {, but were significant at days } 3,7 \text {, and } 14 \text { (all } p<0.0001) \\
\text { Post-hoc analyses comparing time points at each group: } \\
\text { SNL IPSI were significant at days } 3,7 \text { and } 14 \text { when compared with SNL IPSI day }-1(\text { all } p<0.0001) \\
\text { Results indicated SNL IPSI had a higher MLL1 expression in the dorsal horn on days } 3,7 \text {, and } 14 \text { than other groups. }\end{array}$ \\
\hline & \\
\hline
\end{tabular}




\begin{tabular}{|c|c|}
\hline & $\begin{array}{l}\text { One-way ANOVA analysis found that MLL1 siRNA treatment of naïve rats dose-dependently decreased the MLL1 } \\
\left.\text { expression in the dorsal horn ( } F_{(6,28)}=6.985, p=0.0001\right) \text {. } \\
\text { Post-hoc analyses comparing groups: } \\
\text { MLL1 siRNA } 3 \mu \text { g treatment of naïve rats group }(p=0.0057) \text { and MLL1 siRNA } 5 \mu \text { g treatment of naïve rats group ( } p= \\
0.0022 \text { ) were significant when compared with naïve group. }\end{array}$ \\
\hline Fig. 2B & $\begin{array}{l}\text { Two-way ANOVA with Tukey's post-hoc test: } \\
\text { Two-way ANOVA analysis found that the time of performance of MLL1 siRNA treatment with naïve rats was not significant } \\
\text { in main effects of time }(F(4,80)=0.3482, p=0.8445) \text {, group }(F(3,20)=0.5809, p=0.6344) \text {, and group by time interaction } \\
(F(12,80)=1.472, p=0.1525) \text {. } \\
\text { Results indicated the performance exhibited no significant differences between the groups }\end{array}$ \\
\hline Fig. 2C & $\begin{array}{l}\text { Two-way ANOVA with Tukey's post-hoc test: } \\
\text { Two-way ANOVA analysis found that the ipsilateral mechanical threshold of sham rats with MLL1 siRNA treatment } \\
\text { exhibited no significant main effects of time }\left(F_{(4,80)}=1.812 p=0.1347\right) \text {, group }\left(F_{(3,20)}=2.458, p=0.0926\right) \text {, and group } \\
\text { by time interaction }\left(F_{(12,80)}=1.039, p=0.4224\right) \text {. } \\
\text { Results indicated the ipsilateral mechanical threshold has no significant differences between the groups }\end{array}$ \\
\hline
\end{tabular}




\begin{tabular}{|c|c|}
\hline & $\begin{array}{l}\text { esults indicated SNL rats with MLL1 siRNA treatment had a higher mechanical threshold on days } 5 \text { and } 7 \text { than other } \\
\text { oups. }\end{array}$ \\
\hline Fig. 2E & $\begin{array}{l}\text { One-way ANOVA with Tukey's post-hoc test: } \\
\text { One-way ANOVA analysis found that MLL1 siRNA treatment of SNL 7D rats overall decreased the MLL1 expression in } \\
\text { the ipsilateral dorsal horn }\left(F_{(2,12)}=6.291, p=0.0135\right) \text {. } \\
\text { SNL 7D+MLL1 siRNA group }(p=0.0212) \text { was significant when compared with SNL 7D group. }\end{array}$ \\
\hline Fig. 3A & $\begin{array}{l}\text { One-way ANOVA with Tukey's post-hoc test: } \\
\text { One-way ANOVA analysis found that MLL1 siRNA treatment of SNL 7D rats overall decreased the mGluR5 mRNA } \\
\text { expression in the ipsilateral dorsal horn }\left(F_{(3,16)}=66.36, p<0.0001\right) \text {. } \\
\text { Post-hoc analyses comparing groups: } \\
\text { SNL 7D group ( } p<0.0001) \text { was significant when compared with Sham 7D group. SNL 7D+MLL1 siRNA group ( } p< \\
0.0001) \text { was significant when compared with SNL 7D group. }\end{array}$ \\
\hline Fig. 3B & $\begin{array}{l}\text { One-way ANOVA with Tukey's post-hoc test: } \\
\text { One-way ANOVA analysis found that MLL1 siRNA treatment of SNL 7D rats overall decreased the mGluR5 expression } \\
\text { in the ipsilateral dorsal horn }\left(F_{(3,16)}=13.31, p=0.0001\right) \text {. } \\
\text { Post-hoc analyses comparing groups: } \\
\text { SNL 7D group ( } p=0.0006 \text { ) was significant when compared with Sham 7D group. SNL 7D+MLL1 siRNA group ( } p= \\
0.0472 \text { ) was significant when compared with SNL 7D group. }\end{array}$ \\
\hline Fig. 3C & $\begin{array}{l}\text { One-way ANOVA with Tukey's post-hoc test: } \\
\text { MLL1 } \\
\text { One-way ANOVA analysis found that MLL1 siRNA treatment of SNL 7D rats overall decreased the mGluR5 promoter } \\
\text { fragments immunoprecipitated by MLL1-specific antibodies in the ipsilateral dorsal horn }(F(3,16)=9.268, p=0.0009) \text {. }\end{array}$ \\
\hline
\end{tabular}




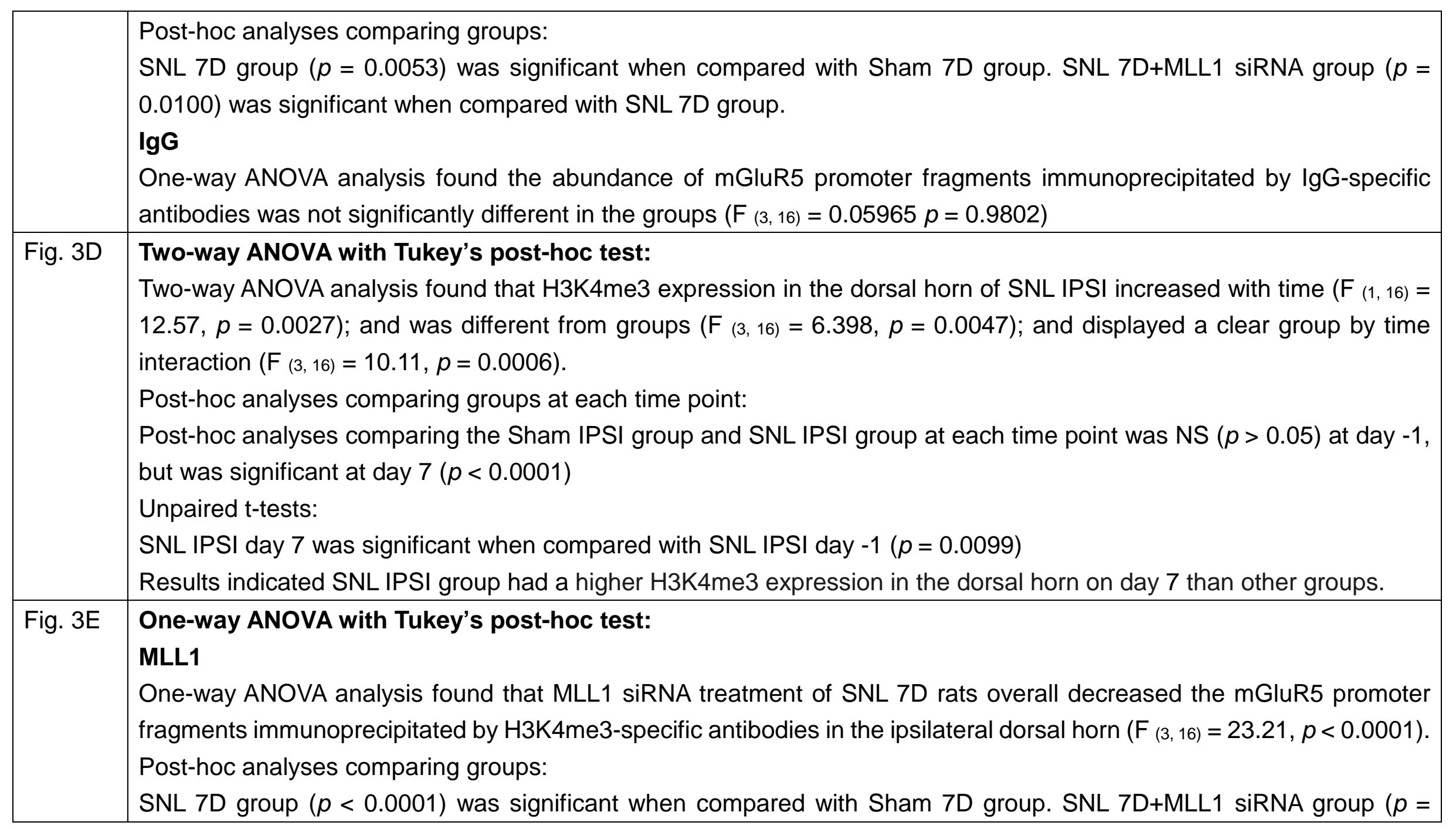




\begin{tabular}{|c|c|}
\hline & $\begin{array}{l}0.0022) \text { was significant when compared with SNL 7D group. } \\
\text { IgG } \\
\text { One-way ANOVA analysis found that the abundance of mGluR5 promoter fragments immunoprecipitated by IgG-specific } \\
\text { antibodies was not significantly different in the groups }(F(3,16)=0.2468 p=0.8611)\end{array}$ \\
\hline Fig. 4A & $\begin{array}{l}\text { Unpaired t-tests: } \\
\text { MLL1 positive cells of SNL 7D were significantly increased when compared with Sham 7D group }(p=0.0028) \\
\text { WDR5 positive cells of SNL 7D were significantly increased when compared with Sham 7D group }(p=0.0019) \\
\text { Merge positive cells of SNL 7D were significantly increased when compared with Sham 7D group }(p=0.0065)\end{array}$ \\
\hline Fig. 4B & $\begin{array}{l}\text { Two-way ANOVA with Tukey's post-hoc test: } \\
\text { Two-way ANOVA analysis found that WDR5 expression in the dorsal horn of SNL IPSI increased with time }\left(F_{(3,48)}=\right. \\
28.36, p<0.0001) \text {; and was different from groups }\left(F_{(3,16)}=52.12, p<0.0001\right) \text {; and displayed a clear group by time } \\
\left.\text { interaction ( } F_{(9,48)}=25.81, p<0.0001\right) \text {. } \\
\text { Post-hoc analyses comparing groups at each time point: } \\
\text { Post-hoc analyses comparing the Sham IPSI group and SNL IPSI group at each time point was NS }(p>0.05) \text { at day }-1 \text {, } \\
\text { but were significant at days } 3,7 \text {, and } 14(p=0.0009, p<0.0001 \text {, and } p<0.0001) \\
\text { Post-hoc analyses comparing time points at each group: } \\
\text { SNL IPSI were significant at days } 3,7 \text { and } 14 \text { when compared with SNL IPSI day }-1 \text { (all } p<0.0001) \\
\text { Results indicated SNL IPSI group had a higher WDR5 expression in the dorsal horn on days } 3,7 \text {, and } 14 \text { than other } \\
\text { groups. }\end{array}$ \\
\hline Fig. 5A & $\begin{array}{l}\text { One-way ANOVA with Tukey's post-hoc test: } \\
\text { One-way ANOVA analysis found that WDR5 siRNA treatment of naïve rats dose-dependently decreased the WDR5 } \\
\text { expression in the dorsal horn }\left(F_{(6,28)}=6.192, p=0.0003\right) \text {. }\end{array}$ \\
\hline
\end{tabular}




\begin{tabular}{|c|c|}
\hline & $\begin{array}{l}\text { Post-hoc analyses comparing groups: } \\
\text { WDR5 siRNA } 3 \mu \mathrm{g} \text { treatment of naïve rats group }(p=0.0256) \text { and WDR5 siRNA } 5 \mu \mathrm{g} \text { treatment of naïve rats group }(p= \\
0.0046) \text { were significantly different when compared with naïve group. }\end{array}$ \\
\hline Fig. 5B & $\begin{array}{l}\text { Two-way ANOVA with Tukey's post-hoc test: } \\
\text { Two-way ANOVA analysis found that the time of performance of WDR5 siRNA treatment with naïve rats was not significant } \\
\text { in main effects of time }(F(4,80)=1.669, p=0.1653) \text {, group }(F(3,20)=2.062, p=0.1376) \text {, and group by time interaction ( } F \\
(12,80)=1.603, p=0.1073) \text {. } \\
\text { Results indicated the time of performance exhibited no significant differences between groups }\end{array}$ \\
\hline Fig. $5 \mathrm{C}$ & $\begin{array}{l}\text { Two-way ANOVA with Tukey's post-hoc test: } \\
\text { Two-way ANOVA analysis found that the ipsilateral mechanical threshold of sham rats with WDR5 siRNA treatment was } \\
\text { not significant in main effects of time }(F(4,80)=1.452 p=0.2247) \text {, group }(F(3,20)=0.8562, p=0.4798) \text {, and group by time } \\
\text { interaction }(F(12,80)=0.8307, p=0.6188) \text {. } \\
\text { Results indicated the ipsilateral mechanical threshold was not significantly different between the groups }\end{array}$ \\
\hline Fig. 5D & $\begin{array}{l}\text { Two-way ANOVA with Tukey's post-hoc test: } \\
\text { Two-way ANOVA analysis found that the ipsilateral mechanical threshold of SNL rats with WDR5 siRNA treatment } \\
\text { decreased with time }(F(4,80)=86.03, p<0.0001) \text {; and was different from groups }(F(3,20)=15.65, p<0.0001) \text {; and } \\
\text { displayed a clear group by time interaction }\left(F_{(12,80)}=4.299, p<0.0001\right) \text {. } \\
\text { Post-hoc analyses comparing groups at each time point: } \\
\text { Post-hoc analyses comparing the SNL+it+WDR5 siRNA group and SNL group at each time point were NS }(p>0.05) \text { at } \\
\text { days }-1,1 \text {, and } 3 \text { but were significant at days } 5 \text { and } 7(p=0.0005, p<0.0001) \\
\text { Results indicated SNL rats with WDR5 siRNA treatment had a higher mechanical threshold on days } 5 \text { and } 7 \text { than other } \\
\text { groups. }\end{array}$ \\
\hline
\end{tabular}




\begin{tabular}{|c|c|}
\hline & $\begin{array}{l}\text { ne-way ANOVA with Tukey's post-hoc test: } \\
\text { ne-way ANOVA analysis found that WDR5 siRNA treatment of SNL 7D rats overall decreased the WDR5 expression in } \\
\text { e ipsilateral dorsal horn }\left(F_{(2,12)}=6.520, p=0.0121\right) \text {. } \\
\text { ost-hoc analyses comparing groups: } \\
\text { NL 7D+WDR5 siRNA group }(p=0.0206) \text { were significant when compared with SNL 7D group. }\end{array}$ \\
\hline & 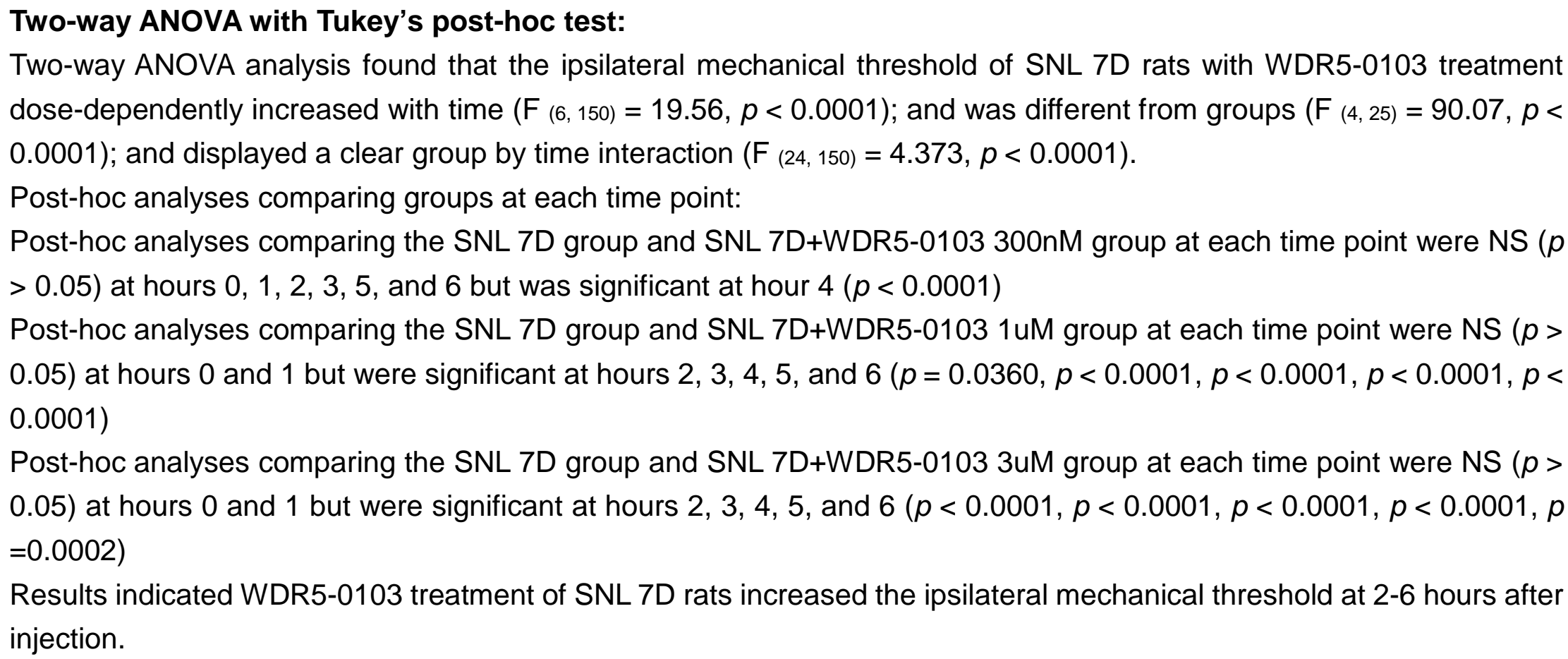 \\
\hline Fig. 6C & ne-way ANOVA with Tukey's post-hoc test: \\
\hline
\end{tabular}




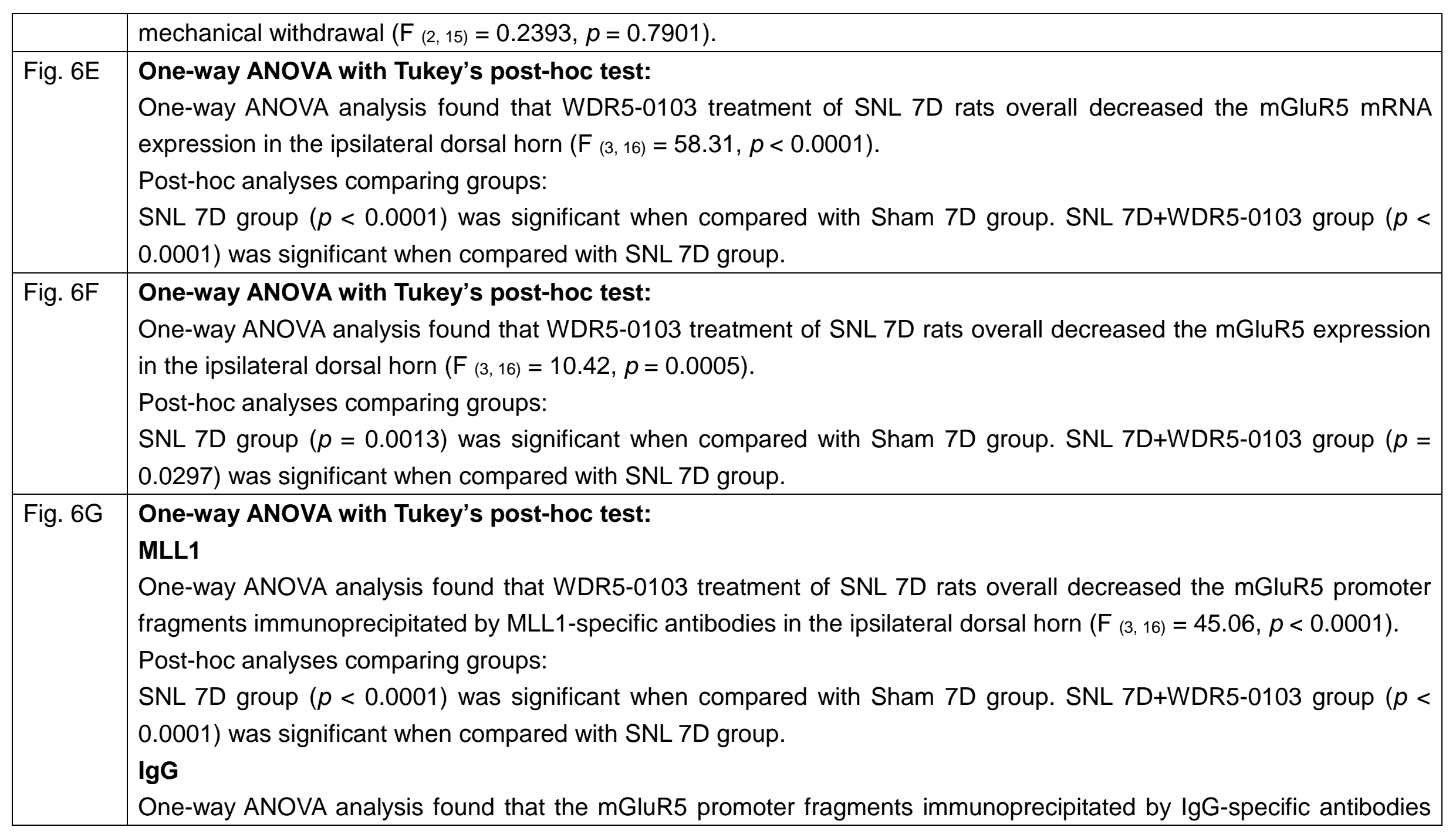




\begin{tabular}{|c|c|}
\hline & $\begin{array}{l}\text { was not significantly different in the groups }\left(F_{(3,16)}=0.4259 p=0.7371\right) \\
\text { WDR5 } \\
\text { One-way ANOVA analysis found that WDR5-0103 treatment of SNL 7D rats overall decreased the mGluR5 promoter } \\
\text { fragments immunoprecipitated by WDR5-specific antibodies in the ipsilateral dorsal horn }(F(3,16)=17.85, p<0.0001) \text {. } \\
\text { Post-hoc analyses comparing groups: } \\
\text { SNL 7D group }(p<0.0001) \text { was significant when compared with Sham 7D group. SNL 7D+WDR5-0103 group ( } p= \\
\text { 0.0068) was significant when compared with SNL 7D group. } \\
\text { IgG } \\
\text { One-way ANOVA analysis found that the mGluR5 promoter fragments immunoprecipitated by IgG-specific antibodies } \\
\text { was not significantly different in groups ( } F(3,16)=0.9241 p=0.4516) \\
\text { H3K4me3 } \\
\text { One-way ANOVA analysis found that WDR5-0103 treatment of SNL 7D rats overall decreased the mGluR5 promoter } \\
\text { fragments immunoprecipitated by H3K4me3-Specific antibodies in the ipsilateral dorsal horn }(F(3,16)=113.9, p<0.0001) \text {. } \\
\text { Post-hoc analyses comparing groups: } \\
\text { SNL 7D group ( } p<0.0001) \text { was significant when compared with Sham 7D group. SNL 7D+WDR5-0103 group ( } p< \\
0.0001) \text { was significant when compared with SNL 7D group. } \\
\text { IgG } \\
\text { One-way ANOVA analysis found that the mGluR5 promoter fragments immunoprecipitated by IgG-specific antibodies } \\
\text { was not significantly different in groups ( }(3,16)=1.296 p=0.3101)\end{array}$ \\
\hline Fig. 7A & Two-way ANOVA with Tukey's post-hoc test: \\
\hline
\end{tabular}




\begin{tabular}{|c|c|}
\hline & $\begin{array}{l}\text { Two-way ANOVA analysis found that the mechanical threshold of SNI IPSI didn't decreased with time }(F(4,64)=2.282, p \\
=0.0701) \text {; but was different from groups }(F(3,16)=90.79, p<0.0001) \text {; and displayed a clear group by time interaction }(F \\
(12,64)=2.365, p=0.0137) \text {. } \\
\text { Post-hoc analyses comparing groups at each time point: } \\
\text { Post-hoc analyses comparing the Sham IPSI group and SNI IPSI group at each time point were NS }(p>0.05) \text { at day }-1 \text {, } \\
\text { but were significant at days } 3,7,14 \text {, and } 21(p<0.0001, p=0.0002, p=0.0003 \text { and } p=0.0004) \\
\text { Post-hoc analyses comparing the time point of each group: } \\
\text { SNI IPSI were significant at days } 3,7 \text { and } 14 \text { when compared with SNI IPSI day }-1(p=0.0036, p=0.0003, p=0.0003 \\
\text { and } p=0.0004) \text {. } \\
\text { Results indicated SNI IPSI had a lower mechanical threshold on days } 3,7,14 \text {, and } 21 \text { than other groups. }\end{array}$ \\
\hline Fig. 7B & $\begin{array}{l}\text { Two-way ANOVA with Tukey's post-hoc test: } \\
\text { MLL1 } \\
\text { Two-way ANOVA analysis found that MLL1 expression in the dorsal horn of SNI IPSI increased with time }(F(2,24)=14.55 \text {, } \\
p<0.0001) \text {; and was different from groups }\left(F_{(3,12)}=8.696, p=0.0024\right) \text {; and displayed a clear group by time interaction } \\
(\mathrm{F}(6,24)=9.848, p<0.0001) \text {. } \\
\text { Post-hoc analyses comparing groups at each time point: } \\
\text { Post-hoc analyses comparing the Sham IPSI group and SNI IPSI group at each time point were NS }(p>0.05) \text { at day }-1 \text {, } \\
\text { but were significant at days } 3 \text { and } 7(p=0.0044 \text { and } p<0.0001) \\
\text { Post-hoc analyses comparing the time point of each group: } \\
\text { SNI IPSI were significant at days } 3 \text { and } 7 \text { when compared with SNI IPSI day }-1 \text { (all } p<0.0001) \\
\text { Results indicated SNI IPSI group had a higher MLL1 expression in the dorsal horn on days } 3 \text { and } 7 \text { than other groups. } \\
\text { WDR5 }\end{array}$ \\
\hline
\end{tabular}




\begin{tabular}{|c|c|}
\hline & $\begin{array}{l}\text { Two-way ANOVA analysis found that WDR5 expression in the dorsal horn of SNI IPSI increased with time }(F(2,24)= \\
7.298, p=0.0033) \text {; and was different from groups }\left(F_{(3,12)}=6.408, p=0.0077\right) \text {; and displayed a clear group by time } \\
\text { interaction }\left(F_{(6,24)}=4.684, p=0.0028\right) \text {. } \\
\text { Post-hoc analyses comparing groups at each time point: } \\
\text { Post-hoc analyses comparing the Sham IPSI group and SNI IPSI group at each time point were NS }(p>0.05) \text { at day }-1 \text {, } \\
\text { but were significant at days } 3 \text { and } 7(p=0.0448 \text { and } p=0.0022) \\
\text { Post-hoc analyses comparing the time point of each group: } \\
\text { SNI IPSI were significant at days } 3 \text { and } 7 \text { when compared with SNI IPSI day }-1 \text { ( } p=0.0011 \text { and } p<0.0001) \\
\text { Results indicated SNI IPSI group had a higher WDR5 expression in the dorsal horn on days } 3 \text { and } 7 \text { than other groups. }\end{array}$ \\
\hline Fig. 7C & $\begin{array}{l}\text { Two-way ANOVA with Tukey's post-hoc test: } \\
\text { Two-way ANOVA analysis found that the ipsilateral mechanical threshold of SNI 7D rats with WDR5-0103 treatment } \\
\text { increased with time }\left(F_{(6,72)}=6.246, p<0.0001\right) \text {; and was different from groups }\left(F_{(2,12)}=82.16, p<0.0001\right) \text {; and } \\
\text { displayed a clear group by time interaction }\left(F_{(12,72)}=4.789, p<0.0001\right) \text {. } \\
\text { Post-hoc analyses comparing groups at each time point: } \\
\text { Post-hoc analyses comparing the SNI 7D group and SNI 7D+WDR5-0103 3uM group at each time point were NS ( } p> \\
0.05) \text { at hours } 0 \text { and 1, but were significant at hour } 2,3,4,5 \text {, and } 6(p=0.0054, p<0.0001, p<0.0001 \text { and } p<0.0001) \\
\text { Results indicated WDR5-0103 treatment of SNI 7D rats increased the ipsilateral mechanical threshold at } 2-6 \text { hours after } \\
\text { injection. }\end{array}$ \\
\hline Fig. 7D & $\begin{array}{l}\text { One-way ANOVA with Tukey's post-hoc test: } \\
\text { One-way ANOVA analysis found that WDR5-0103 treatment of SNI 7D rats overall decreased the mGluR5 mRNA } \\
\text { expression in the ipsilateral dorsal horn }\left(F_{(3,16)}=14.04, p<0.0001\right) \text {. } \\
\text { Post-hoc analyses comparing groups: }\end{array}$ \\
\hline
\end{tabular}




\begin{tabular}{|c|c|}
\hline & $\begin{array}{l}\text { NI 7D group }(p=0.0008) \text { was significant when compared with Sham 7D group. SNI 7D+WDR5-0103 group }(p=0.0018) \\
\text { as significant when compared with SNI 7D group. }\end{array}$ \\
\hline Fig. 7E & $\begin{array}{l}\text { One-way ANOVA with Tukey's post-hoc test: } \\
\text { MLL1 } \\
\text { One-way ANOVA analysis found that WDR5-0103 treatment of SNI 7D rats overall decreased the mGluR5 promoter } \\
\text { fragments immunoprecipitated by MLL1-specific antibodies in the ipsilateral dorsal horn }(F(3,16)=20.87, p<0.0001) \text {. } \\
\text { Post-hoc analyses comparing groups: } \\
\text { SNI 7D group ( } p<0.0001) \text { was significant when compared with Sham 7D group. SNI 7D+WDR5-0103 group ( } p=0.0004) \\
\text { was significant when compared with SNI 7D group. } \\
\text { IgG } \\
\text { One-way ANOVA analysis found that the mGluR5 promoter fragments immunoprecipitated by IgG-specific antibodies } \\
\text { was not significantly different in the groups (F (3,16) = 0.09482 } p=0.9618) \\
\text { WDR5 } \\
\text { One-way ANOVA analysis found that WDR5-0103 treatment of SNI 7D rats overall decreased the mGluR5 promoter } \\
\text { fragments were immunoprecipitated by WDR5-specific antibodies in the ipsilateral dorsal horn (F (3, 16) }=7.760, p= \\
\text { 0.0020). } \\
\text { Post-hoc analyses comparing groups: } \\
\text { SNI 7D group ( } p=0.0130) \text { was significant when compared with Sham 7D group. SNI 7D+WDR5-0103 group ( } p=0.0425) \\
\text { was significant when compared with SNI 7D group. } \\
\text { IgG }\end{array}$ \\
\hline
\end{tabular}




\begin{tabular}{|c|c|}
\hline & $\begin{array}{l}\text { was not significantly different in the groups }(F(3,16)=0.5152 p=0.6776) \\
\text { H3K4me3 } \\
\text { One-way ANOVA analysis found that WDR5-0103 treatment of SNI 7D rats overall decreased the mGluR5 promoter } \\
\text { fragments were immunoprecipitated by H3K4me3-specific antibodies in the ipsilateral dorsal horn }(F(3,16)=45.54, p< \\
0.0001) \text {. } \\
\text { Post-hoc analyses comparing groups: } \\
\text { SNI 7D group ( } p<0.0001) \text { was significant when compared with Sham 7D group. SNI 7D+WDR5-0103 group }(p<0.0001) \\
\text { was significant when compared with SNI 7D group. } \\
\text { IgG } \\
\text { One-way ANOVA analysis found that the mGluR5 promoter fragments immunoprecipitated by IgG-specific antibodies } \\
\text { none significantly different in the groups }\left(\mathrm{F}_{(3,16)}=0.3251 p=0.8072\right)\end{array}$ \\
\hline Fig. 8A & $\begin{array}{l}\text { One-way ANOVA with Tukey's post-hoc test: } \\
\text { MLL1 } \\
\text { One-way ANOVA analysis found that WDR5 siRNA treatment of SNL 7D rats overall decreased the mGluR5 promoter } \\
\text { fragments immunoprecipitated by MLL1-specific antibodies in the ipsilateral dorsal horn }(F(3,16)=52.88, p<0.0001) \text {. } \\
\text { Post-hoc analyses comparing the } 4 \text { groups: } \\
\text { SNL 7D group }(p<0.0001) \text { was significant when compared with Sham 7D group. SNL 7D+WDR5 siRNA group ( } p< \\
0.0001) \text { was significant when compared with SNL 7D group. } \\
\text { IgG } \\
\text { One-way ANOVA analysis found that the mGluR5 promoter fragments immunoprecipitated by IgG-specific antibodies } \\
\text { was not significantly different in the groups }\left(\mathrm{F}_{(3,16)}=0.2693 p=0.8466\right)\end{array}$ \\
\hline
\end{tabular}




\begin{tabular}{|c|c|}
\hline & 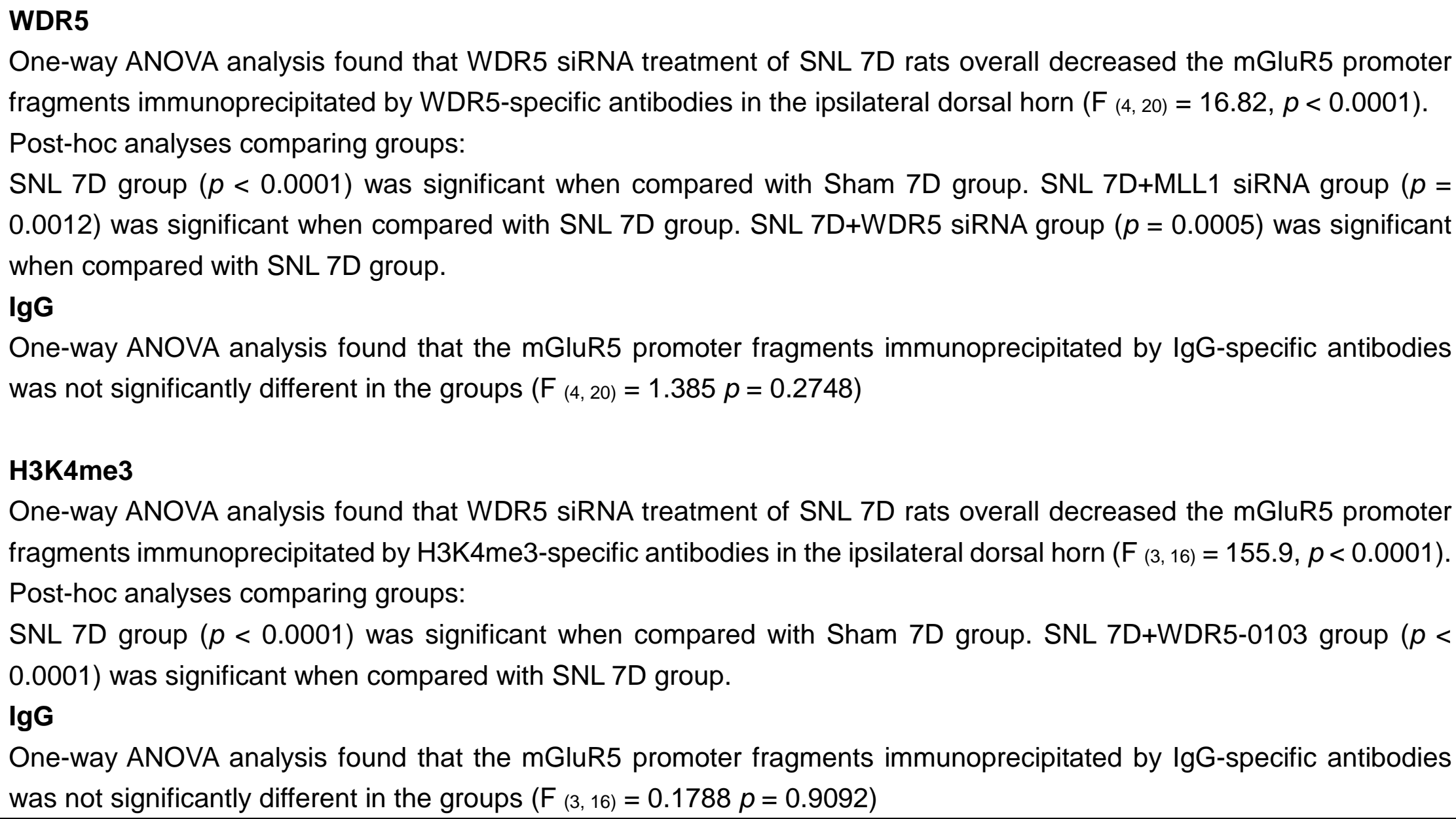 \\
\hline Fig. 8B & One-way ANOVA with Tukey's post-hoc test: \\
\hline
\end{tabular}




\begin{tabular}{|c|}
\hline $\begin{array}{l}\text { MLL1 } \\
\text { One-way ANOVA analysis found that MLL1 siRNA or WDR5 siRNA treatment of SNL 7D rats overall decreased the MLL1 } \\
\text { expression in the ipsilateral dorsal horn }(F(4,20)=15.16, p<0.0001) \text {. } \\
\text { Post-hoc analyses comparing groups: } \\
\text { SNL 7D group ( } p=0.0001) \text { was significant when compared with Sham 7D group. SNL 7D+MLL1 siRNA group ( } p= \\
0.0083 \text { ) was significant when compared with SNL 7D group. SNL 7D+WDR5 siRNA group }(p=0.0296) \text { was significant } \\
\text { when compared with SNL 7D group. } \\
\text { WDR5 } \\
\text { One-way ANOVA analysis found that MLL1 siRNA or WDR5 siRNA treatment of SNL 7D rats overall decreased the WDR5 } \\
\text { expression in the ipsilateral dorsal horn (F }(4,20)=8.513, p=0.0004) \text {. } \\
\text { Post-hoc analyses comparing groups: } \\
\text { SNL 7D group ( } p=0.0042) \text { was significant when compared with Sham 7D group. SNL 7D+MLL1 siRNA group ( } p= \\
0.0199) \text { was significant when compared with SNL 7D group. SNL 7D+WDR5 siRNA group ( } p=0.0098) \text { was significant } \\
\text { when compared with SNL 7D group. } \\
\text { H3K4me3 } \\
\text { One-way ANOVA analysis found that MLL1 siRNA or WDR5 siRNA treatment of SNL 7D rats overall decreased the } \\
\text { H3K4me3 expression in the ipsilateral dorsal horn (F (4, 20) }=8.770, p=0.0003) \text {. } \\
\text { Post-hoc analyses comparing groups: } \\
\text { SNL 7D group ( } p=0.0099) \text { was significant when compared with Sham 7D group. SNL 7D+MLL1 siRNA group ( } p= \\
0.0173) \text { was significant when compared with SNL 7D group. SNL 7D+WDR5 siRNA group ( } p=0.0062) \text { was significant } \\
\text { when compared with SNL 7D group. }\end{array}$ \\
\hline
\end{tabular}




\begin{tabular}{|c|c|}
\hline & $\begin{array}{l}\text { H3 } \\
\text { One-way ANOVA analysis found that } \mathrm{H} 3 \text { expression in the ipsilateral dorsal horn no significantly different in the groups } \\
(\mathrm{F}(4,20)=0.2899 p=0.8811) \\
\text { mGluR5 } \\
\text { One-way ANOVA analysis found that MLL1 siRNA or WDR5 siRNA treatment of SNL 7D rats overall decreased the } \\
\text { mGluR5 expression in the ipsilateral dorsal horn }(F(4,20)=15.39, p<0.0001) \text {. } \\
\text { Post-hoc analyses comparing the } 4 \text { groups: } \\
\text { SNL 7D group ( } p<0.0001) \text { was significant when compared with Sham 7D group. SNL 7D+MLL1 siRNA group ( } p= \\
\text { 0.0026) was significant when compared with SNL 7D group. SNL 7D+WDR5 siRNA group }(p=0.0047) \text { was significant } \\
\text { when compared with SNL 7D group. }\end{array}$ \\
\hline Fig. 8C & $\begin{array}{l}\text { One-way ANOVA with Tukey's post-hoc test: } \\
\text { One-way ANOVA analysis found that CHPG treatment of Naïve rats overall dose-dependently decreased the mechanical } \\
\text { threshold }(F(4,20)=13.77, p<0.0001) \text {. } \\
\text { Post-hoc analyses comparing groups: } \\
\text { Naïve+CHPG 10nm group ( } p=0.0122) \text {, Naïve+CHPG 100nm group ( } p=0.0019 \text { ) and Naïve+CHPG 1um group ( } p= \\
0.0256) \text { group }(p=0.0001) \text { were significant when compared with naïve group. }\end{array}$ \\
\hline Fig. 8D & $\begin{array}{l}\text { One-way ANOVA with Tukey's post-hoc test: } \\
\text { One-way ANOVA analysis found that CHPG treatment reversed WDR5 siRNA treatment of SNL7D rats and MLL1 siRNA } \\
\text { treatment of SNL7D rats increased the mechanical threshold }(F(5,24)=16.49, p<0.0001) \text {. } \\
\text { Post-hoc analyses comparing groups: } \\
\text { SNL 7D group }(p<0.0001) \text { was significant when compared with Sham 7D group. SNL 7D+MLL1 siRNA group ( } p=\end{array}$ \\
\hline
\end{tabular}




\begin{tabular}{|l|l|}
\hline 0.0063) and SNL 7D+WDR5 siRNA group $(p=0.0110)$ were significant when compared with SNL 7D group. SNL \\
7D+MLL1 siRNA+CHPG group $(p=0.0214)$ was significant when compared with SNL 7D+MLL1 siRNA group. SNL \\
7D+WDR5 siRNA+CHPG group $(p=0.0417)$ was significant when compared with SNL 7D+WDR5 siRNA group.
\end{tabular}

